\title{
DESIGN AND ANALYSIS OF WHEEL HEAD IN CUTTER AND TOOL GRINDER
}

\author{
VVSH PRASAD $^{1}$, C. LABESH KUMAR ${ }^{2}$, T. VANAJA $^{3} \&$ K. ASHOK REDDY ${ }^{4}$ \\ ${ }^{1}$ Professor Department of Mechanical Engineering, Institute of \\ Aeronautical Engineering, Dundigal, Hyderabad, India \\ ${ }^{2,3}$ Assistant Professor, Department of Mechanical Engineering, Institute of \\ Aeronautical Engineering, Dundigal, Hyderabad, India \\ ${ }^{4}$ Professor Department of Mechanical Engineering Mlr Institute of Technology, Hyderabad
}

\begin{abstract}
The work is entirely about "Design and Analysis of Wheel Head in Cutter and Tool Grinding Machine ". Wheel

Head is a major part of a grinding machine, which consists of Various sectioned components, namely the wheel head, body, spindle, pulley, bearing housing, column, dial, ring etc., in which each component manufacturing process, dimension and applications are notified in the detailed report. Each sectioned part has to be machined, well before the assembly as per requirement and all sectioned components, are needed to be assembled as per the given procedural steps, for the successful running of wheel head. So, the manufacturing procedure and its dimensions, and other precise instruments calculation have to be notified.
\end{abstract}

KEYWORDS: Design, Analysis, Wheel Head, Tool \& Cutter Grinder

Received: Aug 16, 2017; Accepted: Sep 04, 2017; Published: Sep 13, 2017; Paper Id.: IJMPERDOCT201718

\section{INTRODUCTION}

A tool and cutter grinder as the name indicates is used, for re-sharpening \& manufacturing of cutting tools. There are many types of tool and cutter grinding machine, to meet these requirements. Simple single point tools are occasionally sharpened, by hand on a bench or pedestal grinder. However, tools and cutters with complex geometry like milling cutters, drills, reamers, broaches, taps, boring tools, facing tools and hobs require a sophisticated grinding machine, commonly known as universal tool and cutter grinder. The present trend is, to use tools and cutter grinder equipped with $\mathrm{CNC}$, to grind tool angles, concentricity, cutting edges and dimensional size, with high precision. The operation of this machine (in particular, the manually operated variety) requires a high level of skill. The two main skills needed understanding of the relationship, between the grinding wheel and the metal being cut, and knowledge of tool geometry. The illustrated setup is only one of many combinations available. The huge variety in shapes and types of machining cutters, require flexibility in usage. A variety of dedicated fixtures are included, that allow cylindrical grinding operations or complex angles, to be ground. The vice shown can swivel in three planes. Today's tool and cutter grinder is typically a CNC machine tool, usually 5 axes, which produces end mills, drills, step tools, etc., which are widely used in the metal cutting and woodworking industries? Modern CNC tool and cutter grinders, enhance productivity by typically offering features, such as automatic tool loading, as well as the ability to support multiple grinding wheels. High levels of automation, as well as automatic in-machine tool measurement and compensation, allow extended periods of unmanned production. With careful process configuration and appropriate tool support tolerances, less than 5 micrometres (0.0002") can be consistently achieved, even on the most complex parts. Tool and cutter grinders can be adapted, to manufacturing precision 
machine components. The machine, when used for these purposes are more likely, would be called a CNC Grinding System.

\section{DESIGN OF WHEEL HEAD}

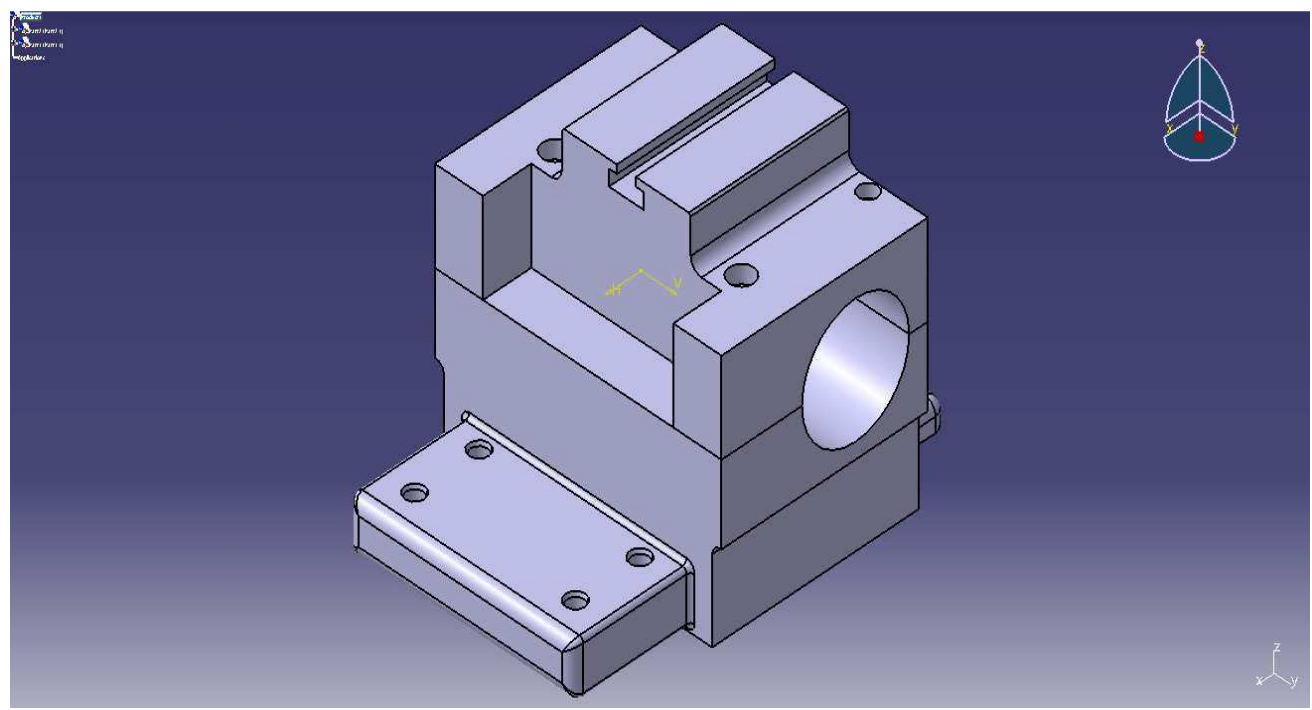

Figure 1: Wheel Head, Body

\section{WHEEL HEAD BODY - Cast Iron gear 30}

Chemical Composition $\mathrm{C}-3.4-3.9 \%, \mathrm{Si}-2.1-2.6 \%, \mathrm{Mn}-0.5-0.8 \%, \mathrm{P}<=0.3 \%, \mathrm{~S}<=0.15 \%$

Table 1: Mechanical Properties

\section{SPINDLE}

\begin{tabular}{|l|c|}
\hline Brinell Hardness & $160-300$ \\
\hline Compressive Strength & $570-1290 \mathrm{Mpa}$ \\
\hline Tensile Strength & $150-450 \mathrm{MPa}$ \\
\hline Young's Modulus & $82-140 \mathrm{GPa}$ \\
\hline
\end{tabular}

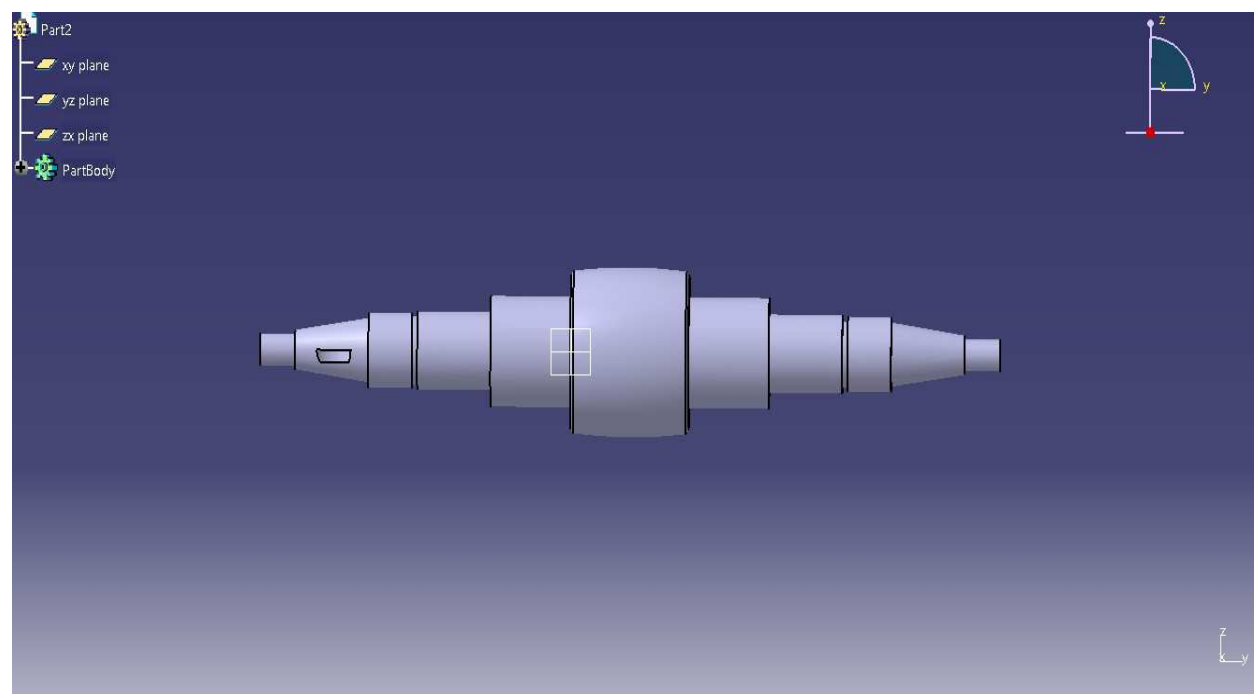

Figure 2: Spindle 


\section{SPINDLE - EN36B (655M13)}

Chemical composition C - $0.10-0.16 \%, \mathrm{Si}-0.10-0.40 \%, \mathrm{Mn}-0.35-0.60 \%, \mathrm{Cr}-0.70-1.00 \%$

Table 2: Mechanical Properties

\begin{tabular}{|l|c|}
\hline Elongation & 15 \\
\hline Tensile Strength & $1100 \mathrm{MPa}$ \\
\hline Brinell Hardness & 341 \\
\hline
\end{tabular}

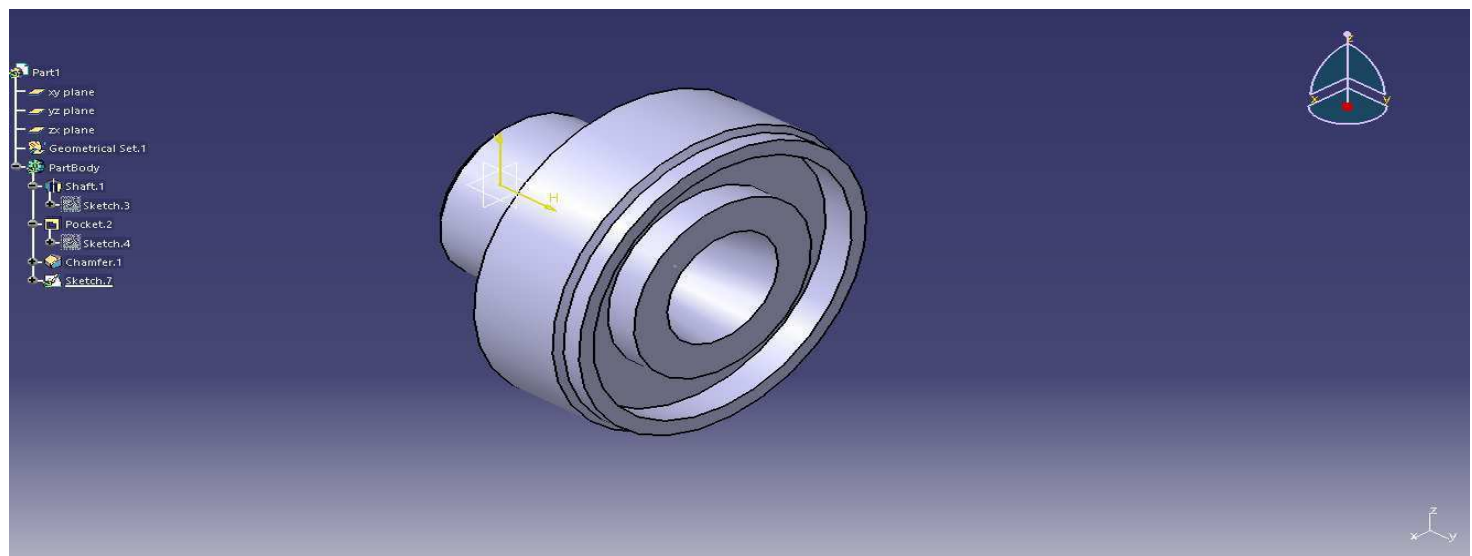

Figure 3: Wheel Flange

\section{WHEEL FLANGE - EN8}

Chemical Composition C $-0.36-0.44 \%, \mathrm{Si}-0.10-0.40 \%, \mathrm{Mn}-0.60-1.00 \% \mathrm{~S}-0.050 \% \mathrm{Max}, \mathrm{P}-0.050 \%$ $\operatorname{Max}$

Table 3: Mechanical Properties

\begin{tabular}{|l|c|}
\hline Yield Stress & $465 \mathrm{~N} / \mathrm{mm}^{2} / \mathrm{min}$ \\
\hline Maximum Stress & $700-850 \mathrm{~N} / \mathrm{mm}^{2}$ \\
\hline Elongation & $16 \%$ \\
\hline Brinell hardness & $201-255$ \\
\hline
\end{tabular}

LH Spindle Nut

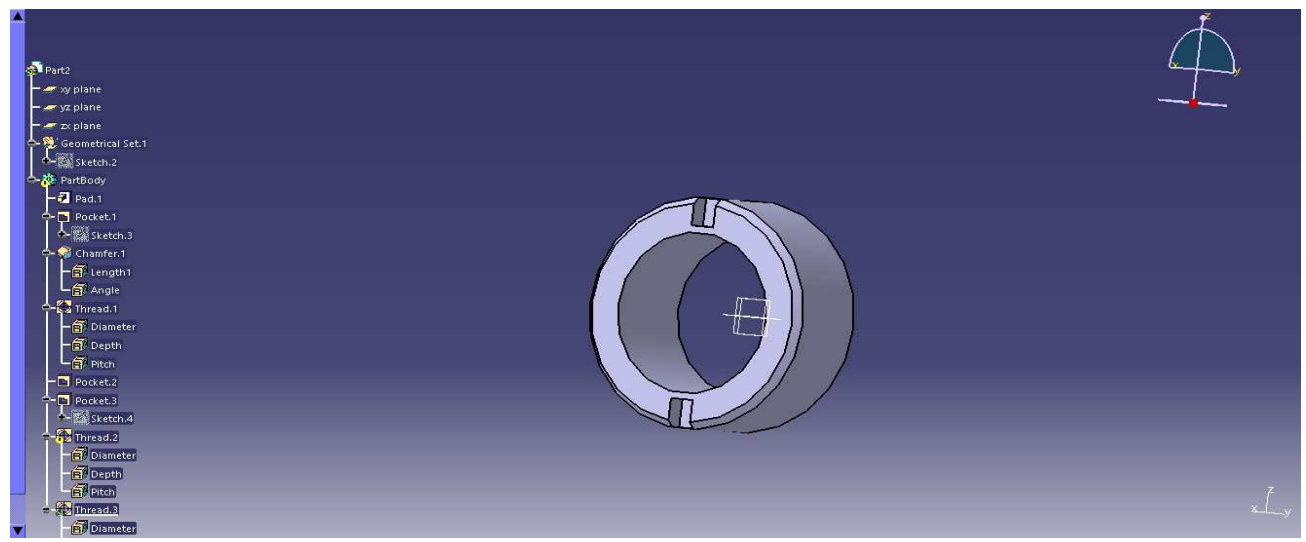

Figure 4: LH Spindle Nut 


\section{RH SPINDLE NUT}

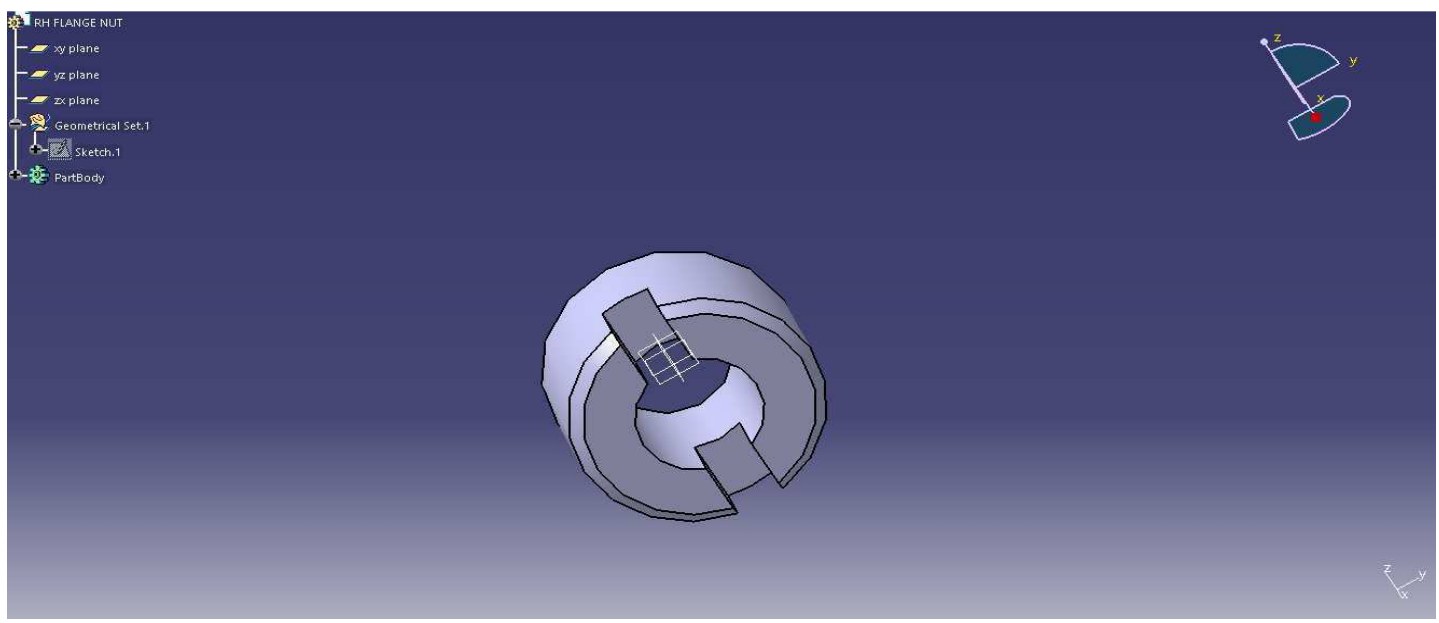

Figure 5: RH Spindle Nut

Spindle Nuts - EN24

Chemical Composition C $-0.36-0.44 \%$, Si $-0.10-0.355 \%$, Mn $-0.45-0.70 \% \mathrm{~S}-0.40 \% \mathrm{Max}, \mathrm{P}-$ $0.035 \% \mathrm{Max}$

Table 4: Mechanical Properties

\begin{tabular}{|l|c|}
\hline Yield Stress & $680 \mathrm{~N} / \mathrm{mm}^{2}$ \\
\hline Elongation & $13 \%$ \\
\hline Brinell hardness & $248-302$ \\
\hline
\end{tabular}

LH Ball Bearing Housing (SKF 7208B Single Row Angular Contact Ball Bearing)

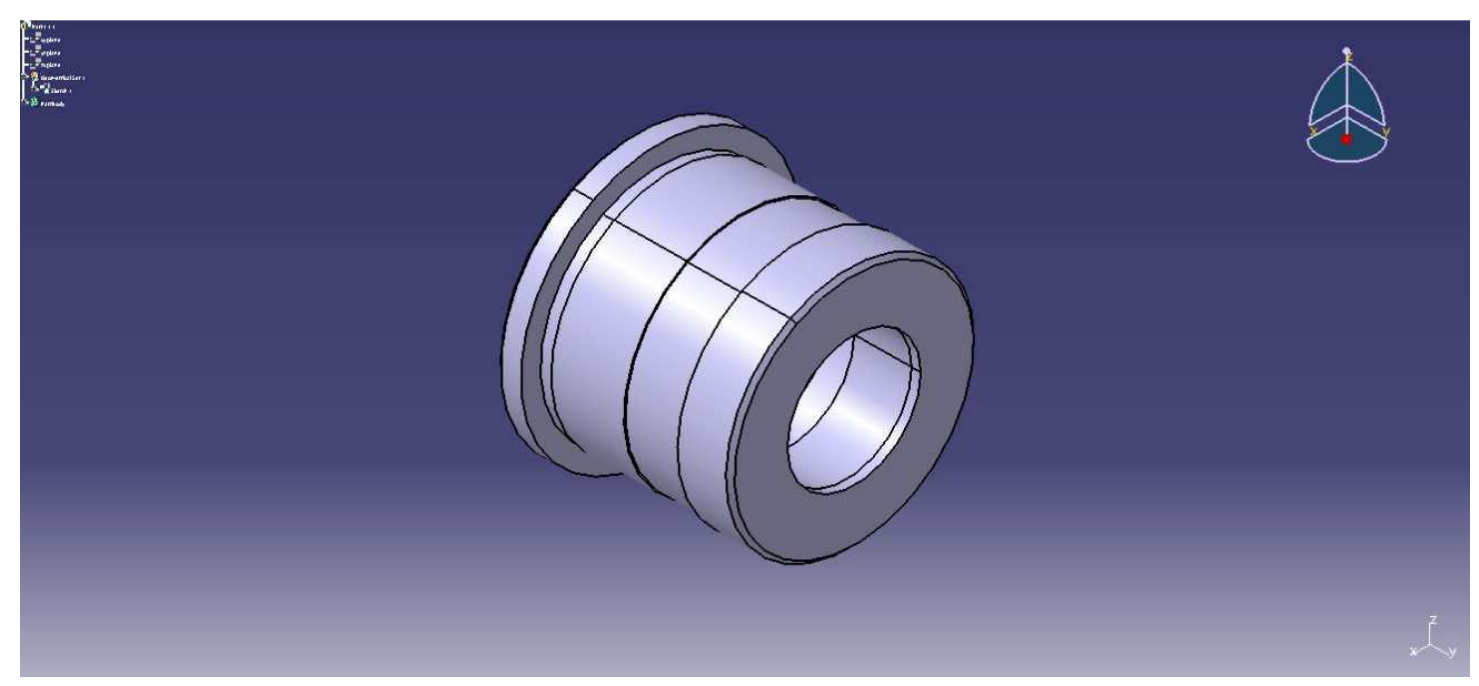

Figure 6: LH Ball Bearing Housing 
RH Ball Bearing Housing (SKF 7208B Single Row Angular Contact Ball Bearing)

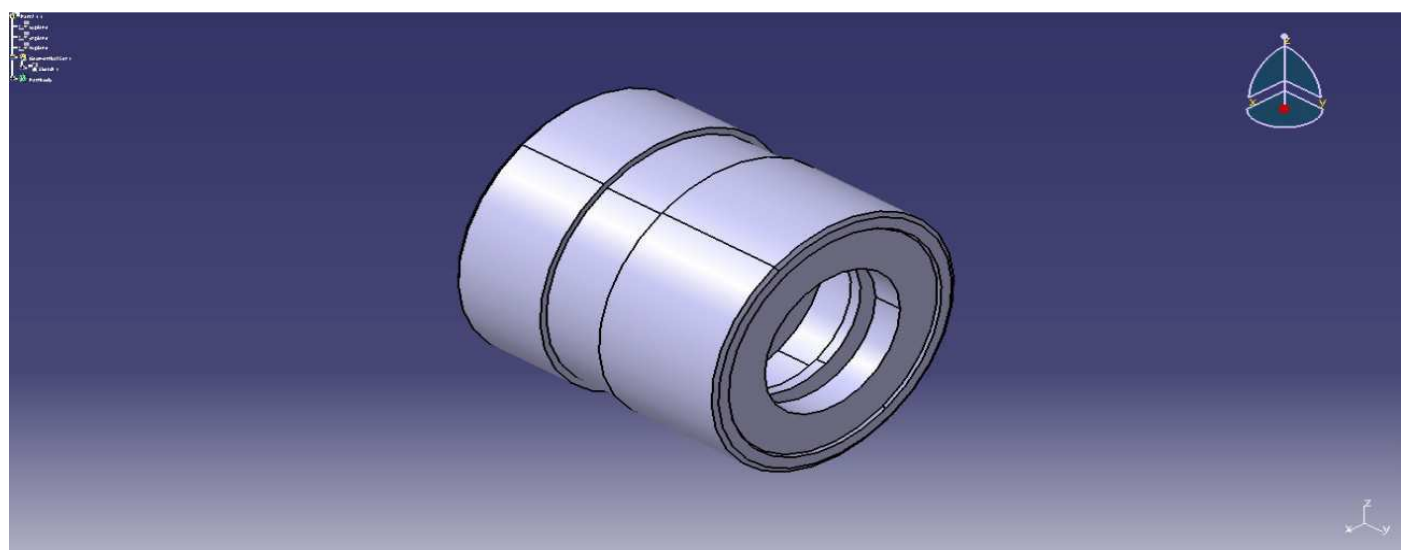

Figure 7: RH Ball Bearing Housing

\section{MOTOR PULLEY}

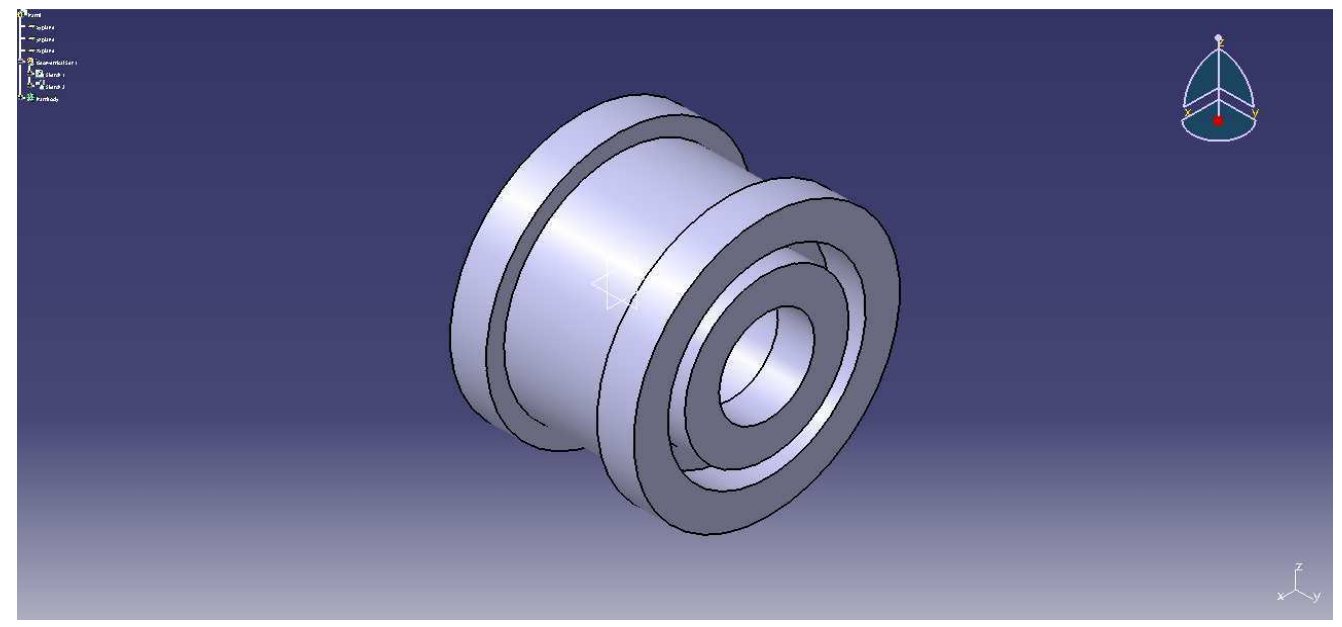

Figure 8: Motor Pulley

\section{WHEEL HEAD ASSEMBLY}

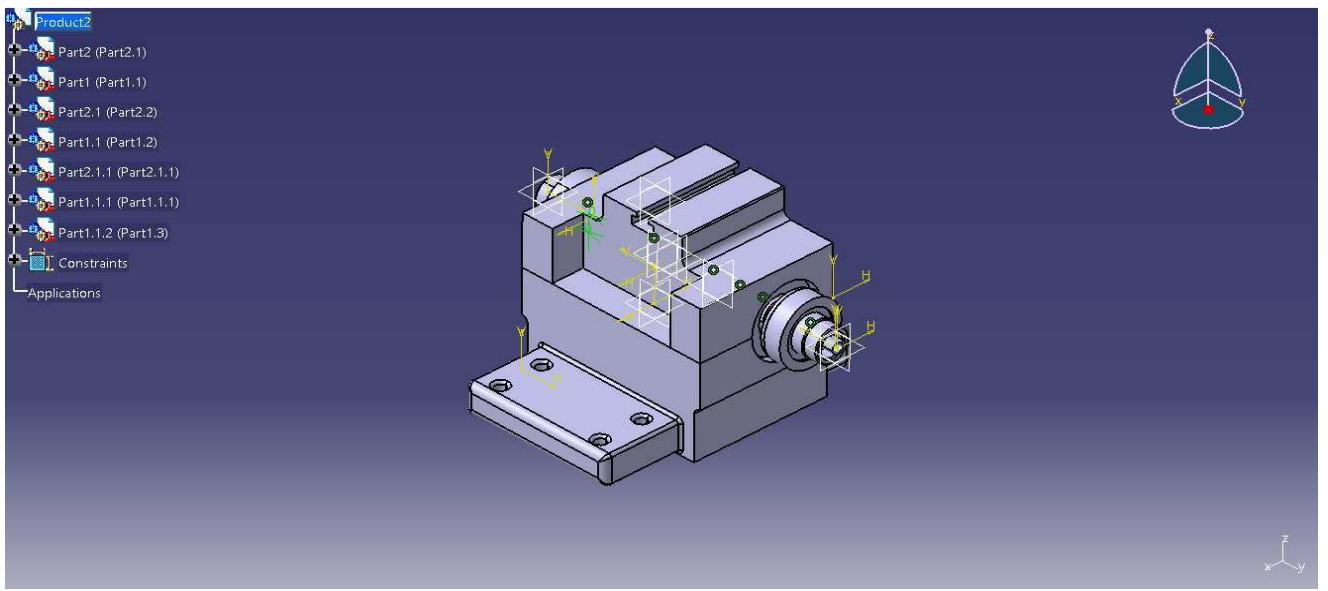

Figure 9: Wheel Head Assembly 


\section{ANALYSIS OF COMPONENTS OF WHEEL HEAD IN TOOL AND CUTTER GRINDER}

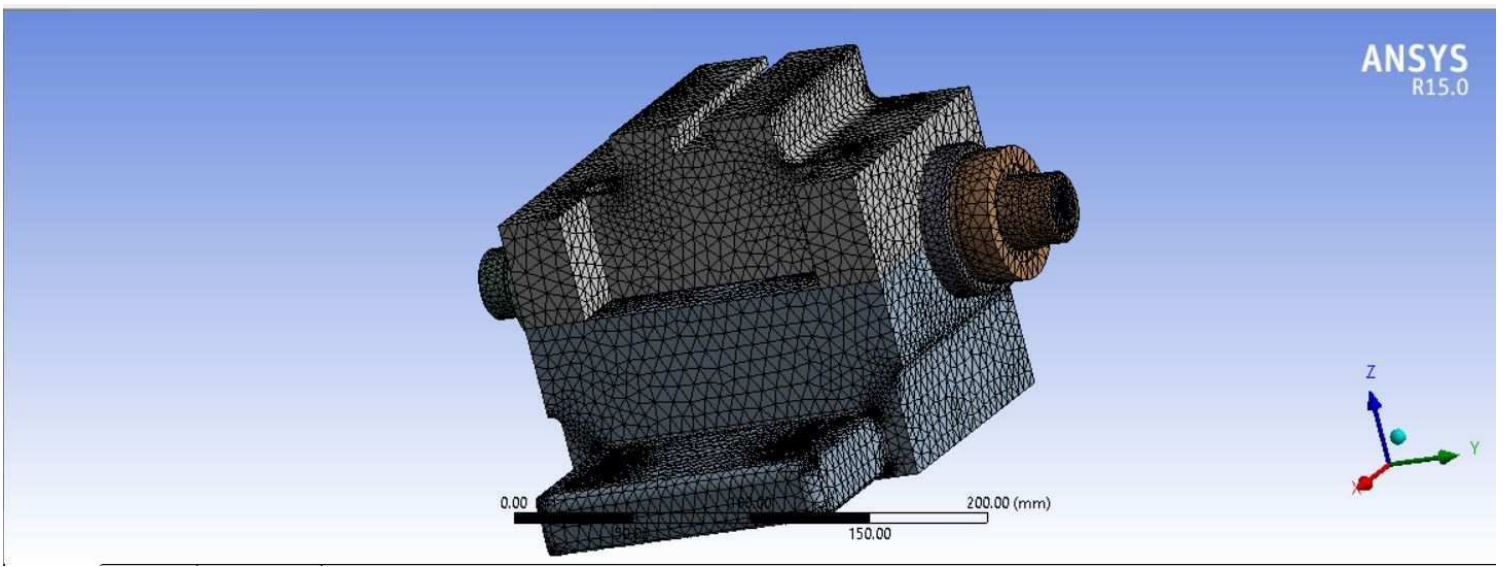

Figure 10: Meshed Wheel Head Assembly

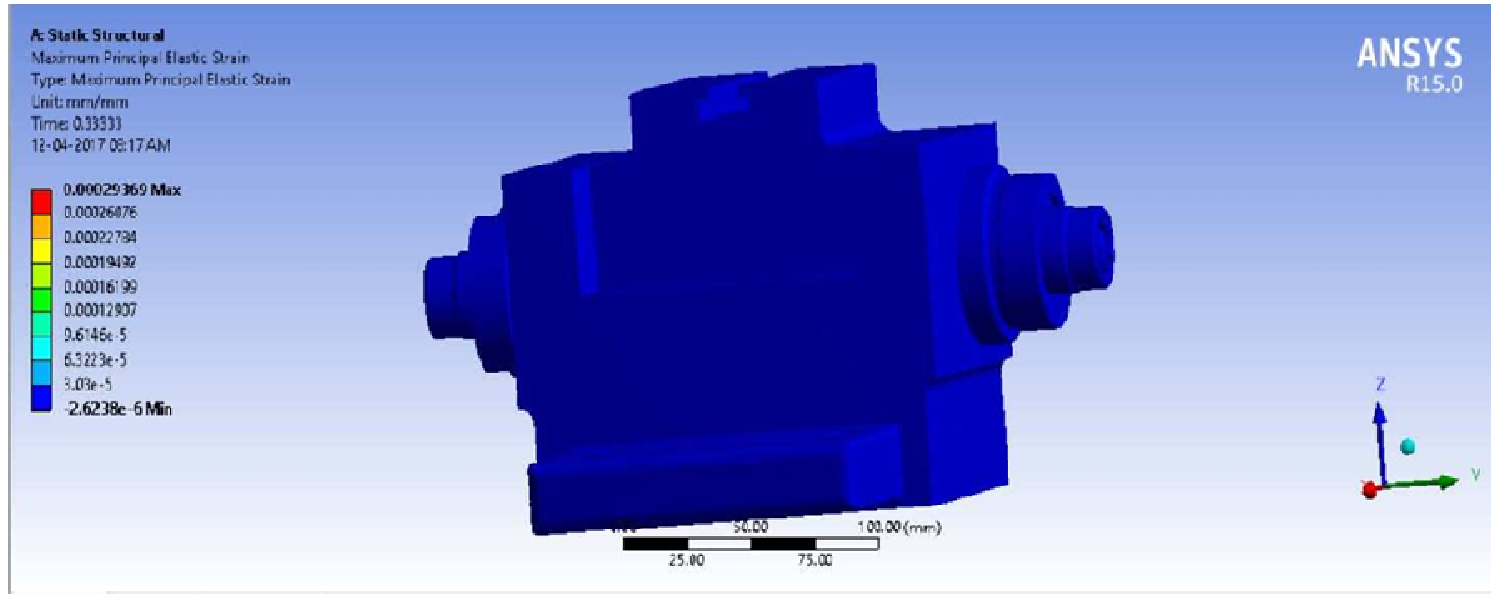

Figure 11: Elastic Strain

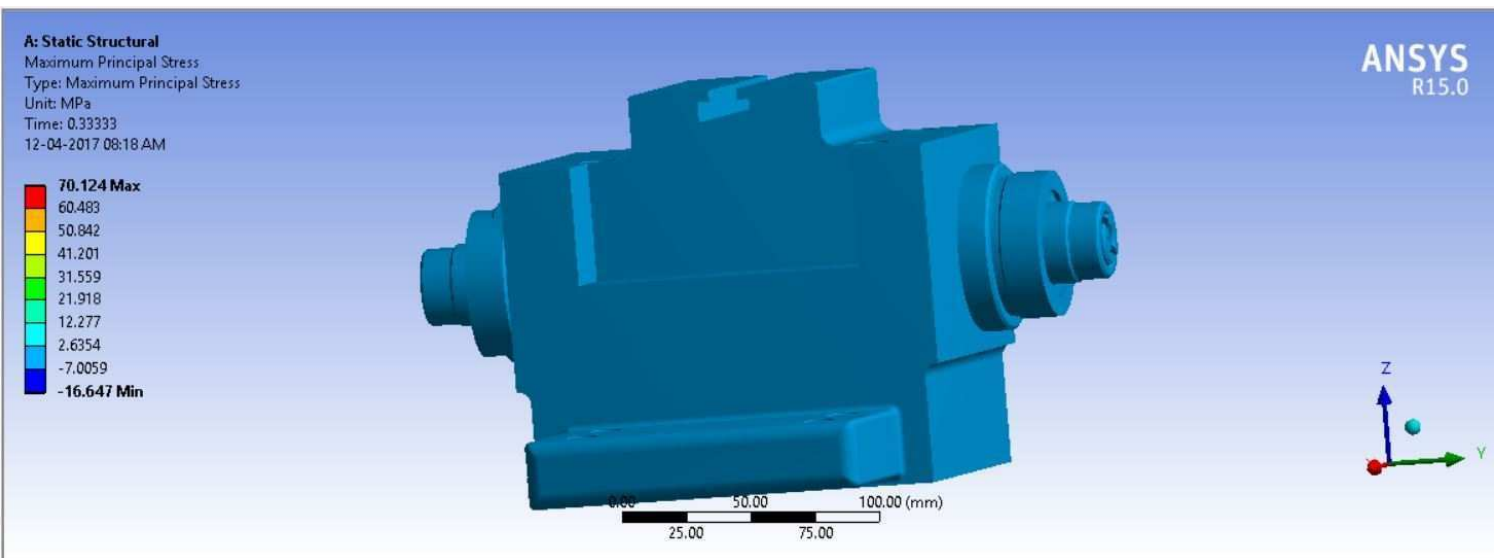

Figure 12: Normal Stress 


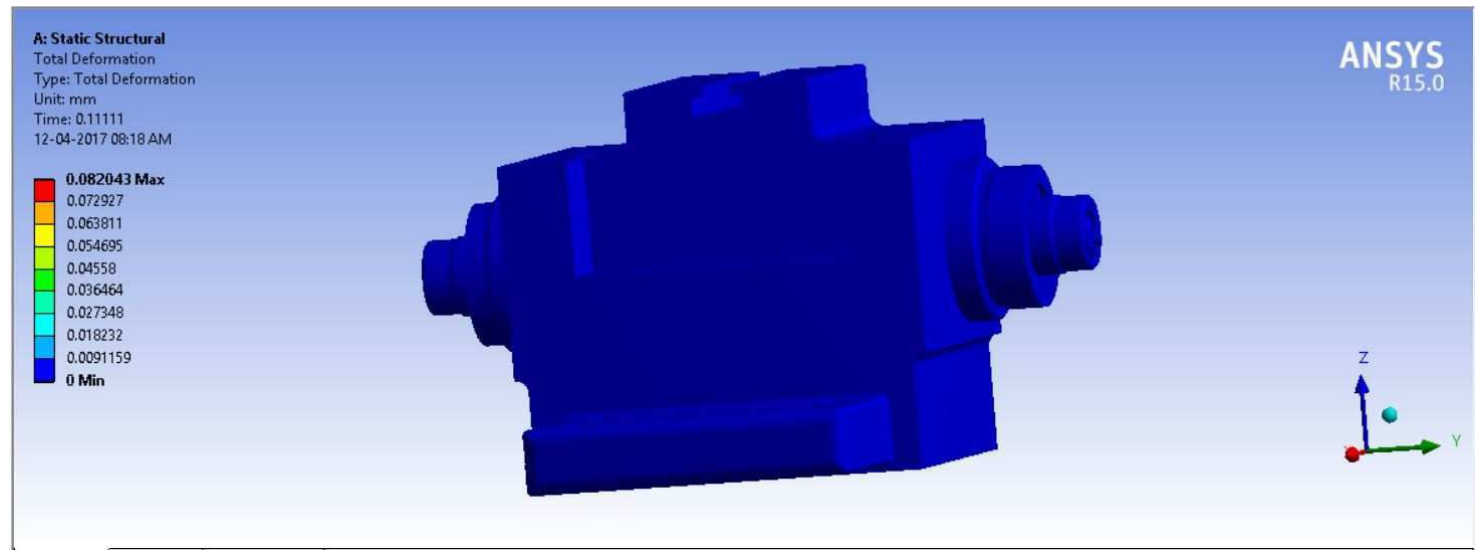

Figure 13: Total Deformation

\section{RESULTS AND DISCUSSIONS}

In the Model analysis of Wheel Head spindle assembly in ANSYS Workbench 15.0, damped Frequencies obtained at different modes are

Table 5

\begin{tabular}{|c|c|}
\hline Mode & Frequency [Hz] \\
\hline 1. & 21.417 \\
\hline 2. & 100.61 \\
\hline 3. & 132.59 \\
\hline 4. & 269.11 \\
\hline 5. & 269.46 \\
\hline 6. & 271.1 \\
\hline 7. & 326.88 \\
\hline 8. & 631.77 \\
\hline 9. & 717.8 \\
\hline 10. & 967.11 \\
\hline
\end{tabular}

- Structural analysis is conducted on the wheel head, body and the maximum deformation is found to be $0.08204 \mathrm{~mm}$ which is satisfactory.

- The maximum stress is found to be $70.124 \mathrm{MPa}$ and maximum elastic strain is found to be 0.00029639 , which is in the satisfactory range.

- Modal Analysis is conducted on Wheel Head body and the fundamental frequency obtained is $27.417 \mathrm{~Hz}$.

- As a part the study of the manufacturing process, of all the components of wheel head assembly.

- Observed the assembly procedures of all the components of the wheel head, and also confirmed the function of wheel head is satisfactory.

- After assembly the wheel head on Cutter and Tool Grinding Machine accuracies are also checked by the quality control. 


\section{CONCLUSIONS}

The design of the spindle is successfully designed in solid work, with all the possible inputs. The structural analysis is conducted for the maximum deformation, which was found to be satisfactory. The surface part of the spindle does not affect, for any deformation value. The possible kind of failure is very low, in terms of the designed spindle. The maximum stress value, for which it can withhold, is limited result. The natural frequencies are extracted, by considering stiffness and mass of the body will not be sufficient, to find critical speed for high speed spindle. Because, the stiffness of the rotating body will be variation depends on the speed. So the speed effects like centrifugal and gyroscopic effects of the spindle bearing system have been considered. Assembly procedures of all the components of wheel head, are being visualized and also confirmed the function of wheel head.

\section{REFERENCES}

1. Y. Lu Y.X. Yao and R.H. Hong "Finite Element Analysis of Thermal Characteristics of High-speed Motorized Spindle “Applied Mechanics and Materials Vols. 10-12 pp 258-262 (2008).

2. Y. Lu Y.X. Yao and W.Z. Xie "Finite Element Analysis of Dynamic Characteristics of High-speed Motorized Spindle” Applied Mechanics and Materials Vols. 10-12 pp 900-904 (2008).

3. Jenq-Shyong Chen Wei-Yao Hsu "Characterizations and models for the thermal growth of a

4. Motorized high speed spindle” International Journal of Machine Tools \& Manufacture $431163-1170$ (2003)

5. Chi-Wei Lin a, Jay F. Tua, Joe Kamman "An integrated thermo-mechanical-dynamic model to characterize motorized machine tool spindles during very high speed rotation "International Journal of Machine Tools \& Manufacture 431035 $1050(2003)$

6. Nagaraj Arakere, Assoc. Prof., Tony L. Schmitz, Asst. Prof., Chi-Hung Cheng "Rotor Dynamic Response of a High-Speed Machine Tool Spindle "University of Florida, Department of Mechanical and Aerospace Engineering 237 MAE-B, Gainesville, FL 326118

7. Jin Kyung Choi, Dai Gil Lee "Thermal characteristics of the spindle bearing system with a gear located on the bearing span 'Department of Mechanical Engineering, Korea Advanced Institute of Science and Technology, ME3221.

8. Gusongdong, Yusong-GU, Taejon-shi, South Korea 305-70 9. Jenq-Shyong Chen*, Kwan-Wen Chen "Bearing load analysis and control of a motorized high speed spindle "International Journal of Machine Tools \& Manufacture 45 1487-1493 (2005). 